\title{
The Cultivation of Academic English Competence for Computer Science Graduates in China Hongbo Song ${ }^{1,}$, Pian Wang ${ }^{1, b^{*}}$
}

${ }^{1}$ College of Foreign Languages, Wuhan University of Science and Technology, Wuhan 430065, P.R. China

a540312904@qq.com, b875060842@qq.com

${ }^{*}$ The corresponding author

\section{Keywords: Academic English competence; Computer science graduates}

\begin{abstract}
As the international academic exchanges become more and more frequent, the demands from English for Academic Purposes (EAP) for computer science graduates also become higher and higher. However, EAP for computer science graduates is in an embarrassing situation in China at the present stage. There are several problems, such as the outdated curriculum, the lack of EAP textbooks, teacher-oriented teaching mode, the lack of opportunities to attend international academic conferences and the lack of competent EAP teachers. This paper puts forward some suggestions to construct EAP teaching mode.
\end{abstract}

\section{Introduction}

During the past several decades, although Chinese some researchers have delivered plenty of high quality English papers successfully, which shows that more researchers' efforts are accepted and China possesses a higher academic position in the world, Chinese researchers are still faced with greater pressure to be acknowledged in international academia. College English for undergraduates has always been the research focus of the policy-makers and experts but only in the recent years that the competence building of EAP for computer science graduates attracts people's attention. While universities go on strengthening and optimizing the developments of professional disciplines, the development of EAP for computer science graduates lags behind.

\section{The Current Situation of EAP for Computer Science Graduates in China}

EAP is a shortened form of English for Academic English, which is a branch of English for Special Purpose (ESP). ESP is concerned with some specific profession or discipline aiming at helping learners to do professional study or research in English. EAP is focused on the teaching aimed at the communication demands and behavior of a specific community in an academic environment. In Hyland and Hymp-Lyons' opinion, EAP is the teaching based on the demands of cognition, society and language of a discipline. [1]

Currently, many universities offer general English courses for graduates, and the overall proficiency of computer science graduates' English has been greatly improved. However, many graduates are still of poor communicative competence. Most graduates still find it hard to make academic exchanges in English. For example, many graduates can hardly understand what the foreign experts are talking about in an academic meeting; when they are required to write an abstract, they will regard it a difficult task; many graduates cannot make an oral presentation fluently even if they can write good papers. There are several problems in EAP for computer science graduates in China.

The Outdated Curriculum. In most universities and colleges, the graduate English courses still focus on general English and only offer English reading and aural-oral courses, which carry on the undergraduate college English mode, with only a slight difference in the difficulty and quantity. At undergraduate level, they have such courses as "College English Listening and Speaking", "College English Reading and Writing". At postgraduate level, they have similar courses as "Graduate 
English Listening and Speaking", "Graduate English Reading and Writing”. To some degree, it is a repetition and a waste of resources and learning time.

The Lack of EAP Textbooks. At present the English textbooks for computer science are mainly focused on the basic writing knowledge and strategies which are similar to the contents of textbooks for college students. Even if the students do well in General English, they find it is hard for them to get understood in academic field because they are not familiar with the technical terms. With the repletion of General English, the students get gradually demotivated in learning English.

Teacher-Oriented Teaching Mode. Many teachers still adopt the traditional teacher-oriented teaching mode. That is, the English teacher plays a dominant role in the class who keeps talking and talking while students are learners who often keep silent and have few chances to speak and they are passive to learn English. As a consequence, students' motivation is becoming weaker and weaker What's more, EAP emphasizes creative and critical thinking. If graduates keep being in the passive learning state and seldom practice their active thinking mind, EAP course would finally descend to be a castle in the air and graduates cannot improve their English for academic writing.

The Lack of Opportunities to Attend International Academic Conferences. Commonly, very few graduates will attend an international academic conference. There are two possible reasons. The first, many graduates do not realize the importance of international academic conference. In fact, international academic conferences, especially famous and high-quality international academic conferences are of great value. A high-quality international academic conference is not only a kind of high-level intelligence activity, but also a highly comprehensive pragmatic arena, which is a collection of academic ideas, experts of this research area, new information about the discipline and the latest research achievements. Attending such academic conferences will benefit graduates a lot. By communicating and exchanging ideas with famous experts, graduates can get a lot of inspirations and new academic information and resources which are valuable to their research in the future. At the same time, as an international academic conference is a kind of pragmatic representation, graduates can practice their listening, speaking, reading, writing, and translation abilities comprehensively. The second, graduates often lack funds to attend such conferences. They have to pay the expense which is a great financial burden to them if there are no funds or allowances.

The Lack of Competent EAP Teachers. Ye [2] believes that a competent EAP teacher in ideal should possess three types of systematic knowledge and competences. The first type is about the knowledge and competence of linguistics and academic discourse. The second type is about the knowledge and competence of English teaching, which include curriculum design, instruction material design and teaching methods. The third type is about the specialized knowledge of one discipline of the teaching objects. Generally, an English teacher often does not have the knowledge or competence of the third type while a Science teacher often does not have the knowledge or competence of the first or second type.

\section{Constructing EAP Teaching Mode for Computer Science Graduates}

With the development of English education, the English proficiency of undergraduates gets better, which means that there are higher demands of English proficiency for graduates. At the present stage, EAP competence cultivation is faced with some problems and challenges, this paper puts forward some suggestions in the hope of constructing EAP teaching mode to improve EAP teaching conditions for Computer Science Graduates.

Optimizing Curriculum and Implementing CBI Model. Curriculum should be based on Students' needs analysis. The postgraduate students are of different English proficiency. Some have passed CET band 4, and some even have passed CET band 6, but a small part of postgraduates do not pass CET band 4. For those students with low English proficiency, the focus should be on general English. But for those students with sufficient English proficiency, the focus should shift to improving their academic English competence.

CBI refers to Content- Based Instruction, which emphasizes the blending of the knowledge of one discipline with linguistic knowledge so that graduates' needs in study and interests in research 
can be integrated[3,4]. The English instruction for Computer Science graduates should integrate the English language teaching with computer science so that the students can communicate orally and in written form in English in their academic field. In order to achieve the goal, such course as English academic writing instruction aiming at international publication and international conference presentation should also be offered.

Selecting or Compiling Proper English Textbooks. The content of the textbook should be based on the content of teaching objects' major, which will interests students and benefit their research. There are two points that should be taken into consideration when selecting English textbooks for graduates. The first is novelty. The development of knowledge is rapid and new research achievements appear constantly. Only the textbooks with latest academic information can guide graduates to progress forward. The second is practicability. The textbook should be closely related with academic exchanges and can guide them on how to do research.

They can also use original computer science textbooks published in English speaking countries so that the students can be immersed in the authentic English.

The English teachers and the Computer Science teachers can work together to compile EAP textbooks according to Computer Science graduates' English proficiency.

Taking Advantage of the Internet and Writing Center. There are numerous resources in the Internet which can broaden graduates' horizon, increase their inputs and be a useful way for graduates to study autonomously. There are many advantages of study on the Internet. Firstly, the internet is free from the restrictions of time and location, which is helpful for graduates to do research autonomously. Secondly, Internet provides graduates convenience as they can communicate with each other at any time about academic matters, which saves them a lot of time and energy.

English Writing center [5] is a good way to improve the students' writing skills. There the graduates can receive one-to-one guidance from their teachers or writing experts. The student who needs to have his or her paper polished can make an appointment with the teacher by phone or by email. Before they decide to hand in a term paper or even issue an academic paper, they can go to the writing center to ask teachers for help. As such a kind of guidance is one to one and face to face communication, the graduates can get professional instructions which help graduates to write good papers.

Organizing or Simulating International Academic Conferences. International academic conferences are of great importance which has been discussed above. Universities can invite eminent experts to organize academic conferences which can provide teachers and students academic exchange chances. If organizing academic conferences is not possible because of the lack of financial aids, universities can simulate such international conferences. By simulating how to give academic speeches graduates can improve their academic competence. [6]

Training Competent EAP Teachers. There was once a debate about what kind of teacher being a competent EAP teacher. The result is that English teacher and science teachers should try to cooperate. $[7,8,9,10]$ On the one hand, both of them share the teaching duties and complete teaching tasks together. On the other hand, their responsibilities should be identified.

\section{Conclusion}

As the competition is fierce, the society puts higher academic demands on graduates, including computer science graduates. However, at the present stage, there are several problems, such as the outdated curriculum, the lack of EAP textbooks, teacher-oriented teaching mode, the lack of opportunities to attend international academic conferences and the lack of competent EAP teachers. This paper puts forward some suggestions, for example, selecting or compiling proper English textbooks, taking advantage of the Internet and writing center, optimizing curriculum and Implementing CBI teaching, organizing or simulating international academic conferences and training competent EAP Teachers, to construct EAP teaching mode. 


\section{Acknowledgement}

This paper is sponsored by the Teaching Research Project of Higher Education of Hubei, China in 2015 entitled "The Construction and Practice of English-Classification curriculum system of graduates of academic/professional degree in Science and Technology Universities" (The project number is2015232).

\section{References}

[1] K.Hyland, L.Hamp-Lyons: EAP: directions and issues [J]. Journal of English for Academic Purposes, 2002 (1).

[2] Y.P.Ye. The development of EAP competence of graduates - the role that English teacher and supervisor [J]. Academic Degrees and Graduate Education, 2014, 09:44-48.

[3] H. Deng: The study of EAP teaching of non-English major graduates based on CBI theory-taking the teaching reform of graduate English teaching of Beijing university of technology [J]. Dongjiang Journal, 2015, 03:101-104.

[4] J.Y. Chang and L. Liu: Content-based teaching mode and the implications for college bilingual teaching [J]. Jiangsu Gaojiao, 2009, 01:81-83.

[5] S. Han and J.X.Wang: The multi-thoughts on EAW teaching of non-English major graduates [J]. Academic Degrees and Graduate Education, 2010, 08:45-49.

[6] J.P.Song: The attempt to simulate to hold an international academic meeting [J]. Academic Degrees and Graduate Education, 1998, 06:25-27.

[7] A. Dudley -Evans, T. F. Johns: A team-teaching approach to lecture comprehension[A]//The teaching of listening comprehension: ELT documents special[C]. London: The British Council, 1981:30-46.

[8] A. Love: Process and product in geology: an investigation of some discourse features of two introductory textbooks [J].English for Specific Purposes, 1991 (10):89-109.

[9] A. Love: Lexico -grammatical features of geology textbooks : process and product revisited [J]. English for Specific Purposes, 1993 (12):197-218.

[10] R. Spack: Initiating ESL students into the academic discourse community: how far should we go[J]. TESOL Quarterly, 1988(22):1. 